\title{
Identidades e regionalização nas
}

\section{minisséries brasileiras ${ }^{1}$}

Felipe de Castro Muanis²

1 Trabalho apresentado na Conferência Internacional Interfaces da Lusofonia, apresentado na Universidade do Minho (UMinho) em Braga, Portugal, 2013.

2 Doutor em Comunicação Social pela Universidade Federal de Minas Gerais (UFMG) com passagem pela Bauhaus Universität-Weimar. Professor adjunto de televisão e mídias digitais do Departamento de Cinema e Vídeo da Universidade Federal Fluminense (UFF). Professor do Programa de Pós-Graduação em Comunicação e Coordenador do grupo de pesquisa ENTELAS. felipemuanis@id.uff.br. 


\section{Resumo}

Palavras-chave

Minisséries de televisão no Brasil tendem a ser espaços mais abertos à experimentação. Ainda assim, tanto sua produção quanto suas temáticas focam preferencialmente no sudeste e nos espaços urbanos, expondo um lado conservador. A raiz desse problema é a dificuldade em regionalizar a produção, algo que é essencial para pensar uma televisão de qualidade no Brasil. A partir das singularidades das minisséries $O$ canto da sereia, Natália e A pedra do reino, pretende-se discutir, neste artigo, como pano de fundo, a necessidade de se regionalizar a produção de minisséries brasileiras para que haja uma reconstituição identitária real, que reflita a pluralidade brasileira e não apenas a da região sudeste, e para que seja possível uma produção e recepção multilateral.

Regionalização, pluralidade, minisséries.

\section{Abstract}

Brazilian television miniseries tend to be proper spaces for experimentation. In spite of that, their production as much as their subjects are focused in the southeast area of the country and its urban centers, revealing a conservative point of view. The main problem is the difficulty to regionalize the TV production, essential to constitute a quality television in Brazil. From the singularities of Brazilian miniseries $O$ Canto da sereia [The mermaid's melody], Natália and $A$ pedra do reino [The stone of the kingdom], this paper intends to debate, as a backdrop, the urge for Brazilian TV miniseries regionalization, which would result in a real reconstruction of identity, reflecting the country plurality instead of solely the southeast region as it would make possible a multilateral production and reception.

\section{Keywords}

Regionalization, plurality, miniseries. 
A televisão é o principal espelho da sociedade: é essencial para a coesão social, que os componentes sociais e culturais da sociedade possam se ver e se referenciar na principal mídia (WOLTON, 2003).

Nascida como TV privada, um dos maiores problemas da televisão brasileira, nos dias de hoje, é a dificuldade de regionalização de programação. Ou seja, de que centros menores e cidades do interior do país façam seus próprios programas tanto para consumo interno como para serem exibidos em outras regiões do Brasil. Ter acesso aos conteúdos regionais, em diversos lugares do país, resultaria em uma maior consciência sobre a diversidade cultural brasileira e romperia os discursos e estéticas hegemônicas, que desde o início da sua televisão, em 1950, dominam nosso imaginário.

A televisão brasileira já teve maior ocupação regional, pelo menos durante dez anos, entre 1950 e 1960. A chegada do videoteipe foi o grande divisor de águas que sedimentou o fim da regionalização de programação. O Brasil vivia, na década de 1960, a ebulição cultural do Teatro Brasileiro de Comédia, do Cinema Novo, do Teatro de Arena e dos programas de rádio, da bossa nova e da MPB, além do ufanismo proporcionado pela conquista das copas do mundo de futebol de 1958 e 1962. Viveu também, a partir de 1964, a ditadura militar, que teve presença ativa em implementar uma política de rede de comunicações por todo o Brasil. Nela, a televisão tinha um papel decisivo, o que também contribuiu para o sucateamento do conteúdo regional.

Diante desse contexto, por que produzir programas televisivos caros em uma emissora do interior do país, custeando recursos humanos e infraestrutura, manutenção de estúdio e equipamentos, sendo possível comprar e transmitir programas de televisão importados das grandes emissoras do eixo Rio-São Paulo, com astros do teatro, do rádio e da música popular brasileira? Desse modo, com atrações de qualidade e preços competitivos, a programação em videoteipe se espalhou a partir do sudeste para todo o Brasil, com uma consequência desastrosa para a produção televisiva no interior do país, diminuiu 
significativamente. O passo seguinte se deu com essas emissoras pequenas se tornando afiliadas e transmitindo em rede a programação das grandes emissoras do sudeste brasileiro, reservando um espaço reduzido de tempo e horário na grade aos programas produzidos localmente. Tal mudança resultou em uma precarização de infraestrutura e da mão de obra, além da falta de interesse, nesses lugares, de refinar seus próprios conteúdos televisivos, suas estéticas e modos de narrar. O resultado é visto hoje de modo contundente: pouco mais de $10 \%$ da programação brasileira é regional, sendo que boa parte dessa frequência se deve aos canais públicos regionais, que reservam em média até $25,5 \%$ de sua grade para conteúdos locais, incluindo reprises ${ }^{3}$.

Pode-se atentar para duas especificidades da regionalização: o tipo de programa e se este é exibido apenas localmente ou para todo o país. Nesse sentido, este trabalho pretende se nortear por um eixo complementar que seria o menos representativo, mas não menos importante, na atual produção regional: os programas de teledramaturgia gravados localmente que almejaram alcance nacional. Ainda que parte das discussões sobre regionalização contemplem prioritariamente os programas realizados localmente e para consumo interno, sem se importar com o conteúdo, o objetivo deste trabalho é justamente ressaltar a importância de problematizar a dificuldade da produção e de distribuição nacional de teledramaturgias locais, reforçando a importância das narrativas televisivas ficcionais.

Nesse sentido, cabe aqui a análise de programas que são gravados fora do sudeste, em outros estados ou no interior do país, mas que não obedecem critérios para serem de fato regionais - ainda que tentem, de alguma forma, mostrarem-se como tal.

Dentre os programas ficcionais, destacam-se as minisséries como os produtos teledramatúrgicos de maior interesse para a discussão que ora se desenvolve. O compromisso da televisão comercial com a audiência, para maximizar o preço do intervalo entre programas e com isso auferir mais lucros,

3 Em estudo feito pelo Observatório do Direito à Comunicação, de 58 emissoras analisadas nas 11 capitais brasileiras, a média de tempo de programação dedicada à produção local foi de 10,83\%. Para maiores detalhes sobre o estudo, acessar: http://www.direitoacomunicacao.org.br/index.php?option=com_docman\&task=doc_download\&gid=441. 
a afasta de riscos e apostas. Desse modo, é a televisão pública que garante, em todo o mundo, o espaço da experimentação. No Brasil, a falta de uma televisão pública forte, já que tradicionalmente ela não investe em teledramaturgia, joga a responsabilidade da experimentação ficcional para os canais abertos privados, que têm nas telenovelas o seu principal produto. Mas estes, por serem narrativas seriadas abertas, mudam de acordo com as demandas do público, buscando garantir maior audiência e, consequentemente, maior retorno pecuniário dos investidores e anunciantes. É nesse cenário que se destacam as minisséries: ficções seriadas televisivas que por serem fechadas e, normalmente, completamente finalizadas antes de começarem a ser exibidas, rompem não com a demanda da audiência, mas com a possibilidade de sofrer interferência em função dos seus resultados. É por esse motivo que as minisséries de televisão, no Brasil, tendem a ser espaços mais abertos à experimentação, já que trabalham com um risco calculado de uma audiência menor. E, sendo posicionadas no fim do horário nobre, durante a noite, destinam-se a um público diferenciado.

No contexto das minisséries e em seu caráter experimental, destacam-se as minisséries feitas pela Rede Globo de Televisão, até pelo fato de ser a emissora líder de audiência e contar com mais infraestrutura. Pode assumir uma margem de risco com relação à audiência que outros canais privados têm menos condições de absorver. A emissora produziu minisséries já consideradas como clássicos da teledramaturgia brasileira, como Lampião e Maria Bonita (1982); Tenda dos milagres (1985), O tempo e o vento (1985); Grande sertão veredas (1985); O primo Basílio (1988); Memorial de Maria Moura (1994); O auto da compadecida (1999); Hoje é dia de Maria (2005), entre outras. Muitas das minisséries brasileiras produzidas pela Globo assumem um caráter nacionalista, tributárias das tradições culturais, literárias e regionais do país. São comuns as adaptações de autores clássicos da literatura, como Guimarães Rosa, Ariano Suassuna, Jorge Amado e Nelson Rodrigues, sendo, muitas vezes, até mesmo exportados para outros países. Desse modo, as minisséries brasileiras, de certo modo, legitimam-se como um espaço de alta cultura na televisão e na Rede Globo. O valor agregado que 
ela gera para emissora é tão importante quanto a audiência, certificando-a como uma televisão que investe em produção nacional de qualidade, com adaptações de clássicos da literatura brasileira, muitas vezes experimentais.

Ainda assim, sua produção parte do sudeste, expondo um lado conservador, do ponto de vista da pluralidade de identidades e regionalização real de seus produtos. Quando trabalham outras regiões do país e a periferia, mesmo das cidades do sudeste, costumam fazer uma apropriação do que entendem por esses espaços, muitas vezes sem abrir de fato um canal de diálogo entre o interior e 0 sudeste rico e urbanizado. Não é que as emissoras não possam fazer produções regionais baseadas no sudeste, mas, por outro lado, também não podem se limitar a essa estrutura de produção. A raiz desse problema é a dificuldade em regionalizar a produção, algo que é essencial para pensar uma televisão realmente de qualidade no Brasil. De acordo com Renato Cordeiro Gomes, são importantes:

(...) as minisséries, que parecem conjugar a exigência de qualidade possibilitada por produção acurada, com o investimento comercial, a exemplo das séries brasileiras, em que a Rede Globo aposta no sucesso comercial em cima de conteúdos referencializados na cultura brasileira e legitimados por adaptações da literatura nacional. Ali também se plasmaria a identidade cultural do Brasil, afinal "a gente se vê por aqui", diz um dos bordões da emissora (GOMES, 2006, p. 2).

A questão que ora se impõe é se, de fato, nos vemos nas minisséries

televisivas e, se não, quem de fato se vê na Rede Globo. É digno de nota que a Rede Globo é a emissora aberta que menos produz conteúdo regional em suas afiliadas, apenas 7\% de média, de acordo com o Observatório de Direito à Comunicação. Nesse sentido, existem minisséries bastante esclarecedoras para a discussão que aqui se segue; uma vinda da televisão pública e duas de uma emissora privada, a própria Rede Globo.

\section{Minisséries e as representações do interior}

Exibida inicialmente na TV Brasil, Natália (2011) foi uma minissérie especial, a primeira incursão de teledramaturgia da TV pública brasileira através 
do edital FIC-TV4. Produzida pela produtora independente Academia de Filmes com a pretensão de se transformar em série, mas não passou da primeira temporada. A série mostra uma menina evangélica e negra, da periferia do Rio de Janeiro, que vira modelo e, consequentemente, lida com os embates naturais de sua adaptação entre os dois mundos.

A segunda minissérie analisada é $A$ pedra do reino (2007), produzida pela Rede Globo e dirigida por Luiz Fernando Carvalho, mas realizada na Paraíba com elenco e mão de obra local. É a adaptação do livro O romance d'a pedra do reino e o príncipe do sangue do vai e volta, do escritor Ariano Suassuna. Ela narra a história de Quaderna que, preso pelo corregedor, conta sua vida, a de um príncipe filho de autênticos reis brasileiros em um sertão alegorizado.

Por fim, como contrapontos às narrativas anteriores, $O$ canto da sereia (2012), também produzida e exibida pela Rede Globo e baseada no livro homônimo de Nélson Motta. É uma microssérie que se passa na Bahia e conta a história do mistério acerca de uma cantora de axé misteriosamente assassinada em cima de um trio elétrico durante o carnaval. Em comum às três narrativas está o deslocamento da centralidade para a periferia, seja do Rio de Janeiro, como em Natália; seja do Brasil, considerando que, no que tange à televisão, sua centralidade econômica e de imaginário se encontra na região sudeste. Nesse caso, O canto da sereia se passa em Salvador, Bahia, e A pedra do reino, em Taperoá, interior da Paraíba, cidade natal de Ariano Suassuna. Tais séries apresentam problemáticas distintas e enfoques específicos sobre uma verdadeira demanda de regionalização na programação brasileira.

Natália parte do embate entre a menina negra e evangélica do subúrbio, tímida e recatada, que desabrocha e aos poucos perde a inocência ao começar a trabalhar na zona sul do Rio em uma agência de modelos. A série não faz uso de um star system grandioso e tem como protagonista a atriz Aisha Jambo, que ainda não despontou com papéis importantes em programas de emissoras abertas.

$\overline{4}$ O edital FIC-TV proporcionou a realização de séries ficcionais para televisão que fossem produzidas por produtoras independentes, exibidas pela primeira vez na televisão pública, em um molde semelhante ao DOC TV. 
Ainda que bem realizada, a série adota nitidamente um enfoque distinto em relação às emissoras privadas, tratando de temas normalmente tabus com mais desenvoltura, como o uso de drogas, religião e o beijo gay masculino - até então inédito na teledramaturgia brasileira. Apesar de alguns diálogos e estruturas maniqueístas, a série tenta retratar o subúrbio carioca de Marechal Hermes, seus hábitos e costumes, bem como o interior de uma família evangélica, sem a construção de estereótipos. Problematiza, nas entrelinhas, questões como o alcoolismo, a falta de perspectiva, o oportunismo e a igreja como negócio. É no embate de valores e estranhamentos entre a zona sul e norte do Rio de Janeiro que a série foca sua narrativa. De fato, essas diferenças, quando bem relacionadas, favorecem o senso crítico e a constituição de identidades.

Em O canto da sereia, tais identidades coletivas se dão menos pela distinção entre os personagens e mais pelo contraste entre os atores que os interpretam. A série conta com dezessete personagens. Destes, oito são nordestinos e outros nove são de outros estados do Brasil, especialmente do eixo Rio-São Paulo ${ }^{5}$. O que difere prioritariamente esses dois núcleos é que os atores nordestinos, pouco conhecidos na grande mídia, mas bastante populares em suas regiões, personificam personagens de apoio, que funcionam mais como "escada" para os personagens principais. Estes, por sua vez, são naturais do sudeste, mas apenas três deles justificam sua naturalidade na narrativa. A maioria, no entanto e de modo evidente, acabam por tentar imitar a fala, o sotaque e os trejeitos do povo baiano.

Por fim, A pedra do reino é a experiência mais radical. A adaptação de Luiz Fernando Carvalho busca ser fiel ao universo do escritor Ariano Suassuna e, de fato, gravou em Taperoá, onde se passa a história. Além de contratar atores e boa parte de pessoas das imediações, criando uma equipe autenticamente regional, com artesãos, carpinteiros e materiais do próprio lugar, dialoga também com a estética da Sagração Armorial, proposta por Suassuna. Ela busca uma arte erudita brasileira tomando como base a cultura nordestina. De fato, a maneira como toda a equipe do sudeste foi para o sertão da Paraíba para se juntar aos 
atores, artistas e trabalhadores nordestinos conferem um grau de autenticidade ao trabalho, de sentir o espaço, de viver o sertão. Para Ariano Suassuna,

\begin{abstract}
Taperoá é a base física da cidade literária que eu construí com toda a minha obra de escritor. Então é uma alegria muito grande ver essa que eu considero a obra mais complexa de todas as que eu escrevi até hoje, ser filmada aqui em Taperoá (...). O sertão não é brincadeira não. O sertão é o nódulo espinhento e pedregoso e belo do Brasil real (A pedra do reino, 2007).
\end{abstract}

A Pedra do Reino não é, de fato, um projeto comum. Faz parte do Projeto Quadrante, idealizado por Luiz Fernando Carvalho a partir de sua experiência com Hoje é dia de Maria, que tem a ambição de contar histórias locais a partir de peças literárias que mapeiam os quatro cantos do Brasil. A primeira das quatro minisséries foi $A$ Pedra do Reino, na Paraíba, seguida por Capitu, adaptação do livro Dom Casmurro de Machado de Assis, no Rio de Janeiro. O projeto se completa com Dois irmãos, baseado no livro de Milton Hatoum, na Amazônia, e Dançar tango em Porto Alegre, baseado na obra de Sérgio Faraco, no Rio Grande do Sul, estas duas ainda por se realizarem. A experiência de mapear o país através de quadrantes baseados na literatura e nas experiências de cada lugar reforçam a visada modernista e antropofágica de Luiz Fernando Carvalho, de acordo com Renato Cordeiro Gomes. Para a figurinista de $A$ pedra do reino, Luciana Buarque,

Desde o início do Projeto Quadrante, que é a ideia inicial do Luiz Fernando de trabalhar com equipes do lugar, de revelar um Brasil que a gente desconhece, precisa se chegar na origem de onde as coisas foram criadas, pessoa que seriam fundamentais nisso que seriam costureiras, bordadeiras, rendeiras, artesãos mesmo, pra fazer adereço. Aí foi um tiro no escuro mesmo mas acreditando que a gente ia conseguir e conseguimos mais do que a gente imaginava realmente (A pedra do reino, 2007).

De acordo com os depoimentos coletados no making-of da série, é visível uma satisfação e orgulho fortes de atores, artistas, trabalhadores e moradores de Taperoá e imediações, que se tomaram parte na série. O fato da equipe ter se deslocado para lá, com o intuito de trabalhar em uma produção bem acabada, adaptando a obra de um importante e renomado escritor brasileiro natural 
da cidade, mostrando Taperoá para o mundo, é motivo de autoestima, talvez fortificada pelo habitual sentimento de estar sempre à margem e de nunca estar no centro dos holofotes. Dona Luzia6, moradora de Taperoá, afirmou emocionada: "Eu tô orgulhosa completamente, tô orgulhosa. Me sentindo morando, como se diz, dentro do céu". Já Dona Rosinha revela, nas entrelinhas de sua fala, a importância de deixar de ser periférica para enfim, ser mostrada na televisão: "Eu tenho certeza que Taperoá agora vai ter valor". Tal sentimento, contudo, não se limita à população local, que poderia apenas estar embevecida com a movimentação trazida por uma equipe de teledramaturgia para quebrar a monotonia da cidade do interior. A atriz Mayana Neiva, também paraibana de Campina Grande, que interpreta uma das personagens, comenta o projeto da série e questiona:

Tem a força do novo. Uma força de trazer o nordeste uma coisa que já é dela mas que parece novo.. É um estranhamento mesmo né? Por que no nordeste não pode ter uma mulher lindíssima, um príncipe, um Quaderna, por quê? Por que nós não temos, merecemos um reinado? (A pedra do reino, 2007).

A pergunta de Mayana Neiva se complementa à postura da atriz Marcélia Cartaxo, que atua tanto em $A$ pedra do reino, quanto em $O$ canto da sereia. Atriz premiada, Cartaxo decidiu há alguns anos retornar do Rio de Janeiro para a Paraíba. Contratada pela Rede Globo, a atriz estava insatisfeita por fazer, nas novelas, apenas papéis de empregada doméstica, reforçando os estereótipos e evidenciando o olhar que o sudeste mantém sobre os nordestinos que migraram. Desse modo, percebe-se que, do ponto de vista do imaginário, o ator nordestino parece receber preferencialmente papéis periféricos nas narrativas, tanto ambientadas no sudeste quanto em suas próprias regiões, como é o caso de $O$ canto da sereia. Diante da impossibilidade de bons papéis, Marcélia Cartaxo voltou para a Paraíba para fazer teatro e aguardar eventuais e raros bons papéis que a demandavam enquanto atriz e não reforçando o estigma de migrante nordestina.

O problema não se restringe à presença de atores e técnicos locais, mas estes também minimizariam outras dificuldades daí decorrentes, como a maneira 
como escritores do sudeste interpretam a realidade regional e a traduzem em suas narrativas. O resultado é um sentimento de incômodo por parte de quem é retratado e de um reforço em estereótipos e falsas idealizações por quem é de outra região e vê a representação. Um caso recente foi a cena do enterro da personagem Damiana, também interpretada por Marcélia Cartaxo, na telenovela Aquele beijo, exibida no dia 20 de outubro de 2011. A cena mostra o cadáver envolto apenas em uma rede e sepultada diretamente na terra, o que indignou espectadores locais por mostrarem uma Paraíba que só tem pobreza e miséria?.

Tais problemas de interpretação não se limitam às leituras regionais sobre o conteúdo que é produzido e exibido no país, a partir do sudeste, mas mesmo em escala mundial. Não é raro ver atores brasileiros imitando o sotaque português para interpretar personagens nativos do país europeu, recebendo inúmeras críticas de seus verdadeiros habitantes. As leituras equivocadas também atravessam o mundo. O programa de televisão "A TV que se faz pelo Mundo", exibido semanalmente pela TV Brasil, revelou em um episódio dedicado ao Quirguistão que o país da antiga URSS consome avidamente as telenovelas brasileiras. Eles comentam que viam e torciam pela personagem Jade da telenovela "O Clone", mas identificavam erros e problemas com relação à sua realidade, a dos muçulmanos, identificando inúmeros estereótipos. De acordo com um pai de família local, nessa novela:

\footnotetext{
latinoamericanos e árabes se tornam amigos, chegam a virar parentes. E encontram coisas em comum, vivem juntos. Mas quando se filma a vida dos muçulmanos, do ponto de vista ocidental, ocorre um distanciamento da realidade e muitas vezes acaba se caindo na caricatura ( $A$ tv que se faz no mundo, 2013).
}

A conclusão,dos espectadores locais é que eles devem e querem fazer suas próprias novelas. Ainda que o episódio tematize outro país que não o Brasil, ele atenta para o fato que as telenovelas brasileiras apresentam generalizações no âmbito internacional e que a construção da interpretação que aqui se faz do 
oriente é cheia de estereótipos e clichês. Mas como o essencial para a emissora é atender ao mercado interno, onde já obtém altos lucros, essas interpretações e leituras mais fiéis às culturas retratadas não são tão importantes. O mesmo acontece com as representações do interior do Brasil, afinal, o público que importa internamente é o da região sudeste, com maior poder aquisitivo, onde se concentram as empresas, as publicidades e as pesquisas de audiência.

A pedra do reino, portanto, é a exceção que confirma a regra. Ainda assim, a minissérie tem um outro lado revelador, além do seu caráter de exceção e da autoestima proporcionada aos moradores e artistas nordestinos. Com todo o talento local visto na série, pergunta-se o porquê de não haver experiências teledramatúrgicas concretas no nordeste e que, além de serem mostradas regionalmente, sejam exibidas nacionalmente. Como lembra Maria Immacolata Vassalo Lopes, "a afirmação de uma identidade se fortalece e se recria na comunicação - encontro e conflito - com o outro" (LOPES, 2004, p. 128). Entender o país e suas identidades é, forçosamente, tomar contato com seus imaginários distintos. Por que então não inverter o vetor do fluxo de produção do sudeste para o resto do país e haver, de fato, uma produção e recepção "multilateral" e não unilateral? Essa inversão, ainda que difícil devido ao fato da televisão brasileira ser fundada em empresas privadas e a programação referenciada por leituras de audiência que se limitam às grandes capitais da região sudeste, faz-se mais que necessária, urgente. De acordo com Cordeiro Gomes,

Esse tipo de ficção midiática - a minissérie brasileira como também a telenovela - desempenha, hoje, um papel decisivo na constituição do imaginário social, semelhante ao folhetim do século XIX e ao romance, que atingiam apenas uma pequena parcela da população brasileira, a letrada, que se amplia com a chegada da tecnologia de comunicação ao correr do século XX. As séries brasileiras de televisão acabam, no entanto, abrindo mão da estratégia discursiva que significa o povo como uma presença histórica a-priori, um objeto pedagógico, que fundaria uma autoridade narrativa (GOMES, 2006, p.8).

O que acontece na teledramaturgia brasileira parece corroborar as análises de Erving Goffman (1985) sobre as regiões de fachada e de fundos. Para o autor, 
em todas as sociedades há um comportamento para a fachada, para onde se reservam a beleza e o que consideram os melhores atributos, enquanto que outras situações são relegadas para a região dos fundos. Goffman está se referindo desde a organização interna das casas e apartamentos, distinguindo os espaços social e de serviço, à distinção entre o palco e os bastidores, até a sociedade como todo. Em um país como o Brasil, onde se faz a distinção em prédios e apartamentos, sobre os espaços destinados a convidados e empregados, não se espanta que essa lógica perversa se instale também na televisão.

O que se vê, desse modo, é uma transposição deste pensamento para as ficções televisivas, especialmente as que se pretendem regionais. De um lado, o que deve ser exibido e enaltecido: a fachada, a representação que deve ser mostrada e a região sudeste como arquétipo desejado de um Brasil ideal por uma classe média alta e urbana, apresentando uma conduta formal e um desfile de olimpianos - para usar o termo de Edgar Morin. De outro lado, o que deve ser ocultado ou que, ao menos não é tão confortável de ser visto: a região dos fundos, o interior do Brasil e o regional, a classe baixa e a pobreza, a periferia, a imagem inacabada ou mal-acabada, uma beleza mais popular e uma conduta mais informal. Goffman lembra que:

Dados os valores de uma determinada sociedade, é evidente que o caráter de bastidor de certos lugares é introduzido neles de modo material, e que, em relação às áreas adjacentes, tais lugares são inevitavelmente regiões de fundo. (...) Os empregadores completam a harmonia contratando pessoas com atributos visuais pouco atraentes para o trabalho na região do fundo e colocando pessoas que "dão boa impressão" nas regiões de fachada (GOFFMAN, 1985, p. 116).

Essa dicotomia é facilmente vista na teledramaturgia brasileira e, de modos diferentes, nas minisséries aqui apresentadas. Natália é uma série que, apesar de algumas estratégias maniqueístas, busca mostrar as nuances dos embates entre a cultura do subúrbio e da zona sul carioca nos conflitos da personagem título. Ao abordar temas mais abertamente, talvez pelo seu canal de exibição ser a televisão pública, afasta-se de representações de subúrbio 
que, de alguma maneira, a reinterpretam, trazendo-a para a aceitabilidade da zona de fachada. Ainda que sejam produtos distintos, é nítida a diferença entre o subúrbio de Natália e o subúrbio idealizado da telenovela Avenida Brasil. Em tempo, enquanto a primeira utilizou locações reais no bairro de Marechal Hermes, a segunda construiu seu próprio subúrbio na cidade cenográfica.

Em O Canto da sereia há divisão entre dois blocos de atores: o primeiro que representa o bloco da fachada, com atores que vêm do sudeste e que são os personagens principais, com maior número de falas. O segundo bloco, da região dos fundos, com atores nordestinos, que fazem personagens secundários, escada para os atores da fachada ou um elenco de apoio ${ }^{8}$. Como limitar-se ao local de gravação para caracterizar a produção regional se os próprios artistas locais são alijados da narrativa em seu próprio ambiente? A pedra do reino, por outro lado, parte de uma consciência da importância de buscar a essência do nordeste através da cidade, seus artesãos e seus artistas, ainda que isso não seja determinante para gerar a ideia de autenticidade tanto de nordeste quanto de Brasil. Não parece se envergonhar do seu "Brasil profundo", conforme afirma Luiz Fernando Carvalho, e, pelo contrário, busca trazer e levar para o resto do país, um pouco do que é regional. De certo modo, e guardadas as devidas proporções, é como uma tentativa de Luiz Fernando Carvalho repetir o movimento para o interior do país feito por Euclides da Cunha em Os sertões.

\section{Considerações finais}

Os exemplos de minisséries aqui apresentadas são complementares. Demonstram apenas que, de modos distintos, as minisséries, espaços propícios para a experimentação, reproduzem as limitações da televisão brasileira. Uma 8 Núcleos, seus personagens, atores e naturalidades. "Sudeste": Sereia (Ísis Valverde - Aiuruoca, MG), Mara (Camila Morgado - Petrópolis, RJ) governador Jotabê - Juracy Bandeira (Marcos Caruso - São Paulo, SP), Augustão (Marcos Palmeira - Rio de Janeiro, RJ), Tuta (Marcelo Médici - São Paulo, SP), Mãe Marinna de Oxum (Fabíula Nascimento - Curitiba, PR), Paulinho de Jesus (Gabriel Braga Nunes - São Paulo, SP), Tia Celeste (Zezé Mota - Campos dos Goytacazes, RJ), Maicon Santos/Dedé (Val Perré - matador - Rio de Janeiro, RJ). Núcleo nordeste: Delegada Marta Pimenta (Margareth Menezes - Salvador, BA) Juarez (Frank Menezes - BA), Só Love (João Miguel - Salvador, BA), Jorge de Ogum (Guilherme Silva - namorado da mãe Marina), Vavá de Zefa (assistente Augustão - Fábio Lago Ilhéus, BA), Salete (parenta de Sereia - Marcélia Cartaxo - Cajazeiras, PB), Geraldo da Silva (AC Costa - marido de Salete - Salvador, BA), policial Rúbens Marques (Antonio Fábio - Coaraci, BA). 
televisão privada que, desde cedo, perdeu suas possibilidades de regionalização de programação. A teledramaturgia brasileira deveria buscar a regionalização ao invés de reproduzir estereótipos e separar regiões de fachada e de fundo, considerando as expectativas de um país que se vê através dos valores, narrativas e estéticas do sudeste. Características das séries apontadas aqui não podem nem ser a praxe (O canto da sereia) e nem a exceção ( $A$ pedra do reino). Por outro lado, falta ainda que o país veja produções locais, para enriquecer o imaginário. Há um inegável e crescente interesse, tanto de público quanto do próprio universo midiático, por temáticas regionais ou periféricas, como os bem sucedidos programas da apresentadora Regina Casé, também na Rede Globo de Televisão.

Todavia, é importante ressaltar que a defesa que aqui se faz da necessidade por um aumento de programação regional, não significa que essa produção deva sempre espelhar uma cultura local. Nada impede que o produtor local tenha a liberdade de fazer qualquer tipo de programa ou gênero com quaisquer atores. Ainda assim, será um programa feito localmente, o que enriquecerá a grade e dará mais pluralidade à televisão. Regionalizar a programação não é sinônimo de buscar um Brasil real ou autêntico - o que é impossível - mas mostrar suas diferentes possibilidades de discursos nos diferentes locais e, com isso, ampliar a percepção do espectador.

De acordo com Edgar Morin, o "sincretismo é a palavra mais apta para traduzir a tendência a homogeneizar sob um denominador comum a diversidade dos conteúdos" (MORIN, 2002, p. 36). Deve-se pensar, portanto, que a regionalização torna-se indispensável para propiciar a diversidade de conteúdos na televisão brasileira. Buscar uma televisão de qualidade no Brasil não deve se limitar a uma aproximação das discussões teóricas oriundas dos Estados Unidos de meados da década de 1980, com Jane Feuer, George Mulgan, entre outros. Também não deve se restringir à melhor imagem, ao "padrão Globo de qualidade" ou à melhor estrutura de produção para construir a imagem da fachada. Em um país com a dificuldade de democratizar a televisão e pluralizar seus discursos, torna-se urgente criar outros vetores dos discursos, possibilitar 
que emissoras regionais invistam em teledramaturgia local e que tenham sua exibição garantida para todo o país.

Desse modo, seriam fortalecidos os traços identitários no Brasil, minimizados os preconceitos calcados em estereótipos e clichês e seria ganha uma grande contribuição no campo narrativo e estético em todo o país, havendo influências mútuas por todo canto. Assim, atores nordestinos bem como de todos os recônditos do país, ainda que alguns ganhem protagonismo em produções no eixo Rio-São Paulo, não precisariam se limitar aos papéis de segunda classe em produções do sudeste, realizadas em suas cidades. O trabalho de atores locais foi essencial para Luiz Fernando Carvalho em $A$ pedra do reino, e afirmou que "soaria tristemente imitativo, falar de um Brasil tão profundo através de representantes oficiais" ${ }^{\prime \prime}$. Ao mesmo tempo, a população regional poderia sempre se orgulhar de ver seu imaginário espalhado pelo Brasil, sem se sentir esquecida como uma região de fundo para onde nunca se joga luz.

Para a constituição de uma nova realidade teledramatúrgica, a televisão brasileira necessita de uma mudança na postura das emissoras e realizadores de televisão, de uma política de governo de regulamentar as comunicações, favorecer o investimento e à infraestrutura de emissoras locais e exigir regionalização de programação - já prevista em lei - para possibilitar o vetor do interior para o todo o país e não apenas o interior receber o vetor do sudeste. Também deve haver a política de fortalecer a televisão pública para permitir a existência e o incentivo desses imaginários. Com essas conquistas seria uma questão de tempo para se espalhar por todo o Brasil sua pluralidade de discursos e nos reconhecermos em nossas identidades possíveis. 


\section{Referências}

A tv do Quirguistão. Programa A tv que se faz no mundo. Rio de Janeiro: TV Brasil, 30 mai. 2013, 23h. Duração: 30 min.

GOFFMAN, E. A representação do eu na vida cotidiana. São Paulo: Vozes, 11a ed., 1985.

GOMES, R. C. "Matrizes culturais e formatos industriais: uma série brasileira de televisão". In: $15^{\circ}$ encontro anual da Associação Nacional dos Programas de PósGraduação em Comunicação (Compós). 2006. Bauru. Anais... Bauru: UNESP, 2006.

LOPES, M. I. V. "Para uma revisão das identidades coletivas em tempo de globalização". In: LOPES, M. I. V. (Org.). Telenovela: internacionalização e interculturalidade. São Paulo: Loyola, 2004. 250 p. pp. 123-126.

MORIN, E. Cultura de massas no século XX: neurose. Rio de Janeiro: Forense Universitária, 2002.

MUANIS, F. "La pire des télévisions est 'moins pire' que pas de télévision du tout". Colloque Qu'est-ce que une télévision de qualité. Paris: CEISME/Sorbonne Paris III,10/12 sept. 2012.

TAPEROÁ. making-of. DVD A pedra do reino. Rede Globo, 2007.

VALENTE, J. C. L. Produção regional na tv aberta brasileira: um estudo em 11 capitais brasileiras. Observatório do Direito à Comunicação. Disponível em: http:// www.direitoacomunicacao.org.br/index.php?option=com_docman\&task=doc_ download\&gid=441. Acesso em: 15 jun. 2013.

WOLTON, D. Internet, e depois? Porto Alegre: Sulina, 2003. 